\title{
ANÁLISE DA VIABILIDADE PARA APLICAÇÃO DE PROJETOS DE EDUCAÇÃO AMBIENTAL DO PONTO DE VISTA DOS ATORES INSTITUCIONAIS ENQUANTO PARTICIPANTES
}

\author{
Cynthia Aves Félix de Sousa ${ }^{1}$ \\ Arilde Franco Alves ${ }^{2}$ \\ Tânia Maria de Andrade ${ }^{3}$ \\ Sinara Cybelle Turíbio e Silva Nicodemo ${ }^{4}$ \\ Gustavo Oliveira Vitorino ${ }^{5}$
}

Resumo: A pesquisa se propôs a investigar o potencial motivacional dos atores sociais institucionais para ações em prol do meio ambiente, tendo em vista que as instituições de ensino são essenciais na conscientização ambiental. Para tanto, este estudo de caso utilizou-se de uma metodologia de cunho exploratório com abordagens quantitativas e qualitativas. Questionários foram aplicados com uma amostra de possíveis participantes de projetos de Educação Ambiental que poderão ser desenvolvidos nas instituições de ensino. Os resultados indicaram que há um relevante interesse por parte dos atores institucionais em participar de projetos de Educação Ambiental, apesar dos diferentes desafios a serem enfrentados no contexto discente, docente e da gestão escolar.

Palavras-chave: Educação Ambiental; Projetos de Educação Ambiental; Atores institucionais.

1 Universidade Federal da Paraíba. E-mail: cynthiaalvesfs@hotmail.com

2 Instituto Federal da Paraíba. E-mail: francalves11@hotmail.com

3 Instituto Federal da Paraíba. E-mail: Tânia.andrada@ifpb.edu.br

${ }^{4}$ Instituto Federal do Rio Grande do Norte. E-mail: sinara.cybelle@gmail.com

${ }^{5}$ Centro Universitário de João Pessoa. E-mail: gustavo_oliveira_vitorino@hotmail.com 


\section{Introdução}

A situação ambiental vigente tem sido cada vez mais atribuída à falta de conscientização ambiental da espécie humana, refletida nos hábitos e escolhas diárias, tanto na escala individual quanto na coletiva.

No campo acadêmico, as discussões acerca das consequências ambientais negativas de um desenvolvimento insustentável apontam para a necessidade de uma abordagem holística no processo de compreensão das temáticas ambientais. Assim, uma visão holística a respeito da sustentabilidade permite a observação sobre a complexidade existente em torno das interações entre os sistemas sociais e ambientais. Essas interações tornam o debate sobre o desenvolvimento sustentável amplo e multidisciplinar (MARTINS; CÂNDIDO, 2008).

Leff (2000) aborda que para o alcance de um modelo de desenvolvimento sustentável é necessário uma mudança da racionalidade econômica para uma racionalidade ambiental, cujas principais característica são a legitimação social e o reconhecimento da natureza como elemento integrado ao sistema econômico. Assim, os propósitos da sustentabilidade implicam em uma reconstituição dos padrões do desenvolvimento.

Nessa perspectiva, a educação tem papel relevante, visto que o ambiente escolar, por sua importância social, é capaz de exercer influência nos processos de formação educacional do indivíduo e, consequentemente, no âmbito social coletivo.

Assim, a aplicação e o desenvolvimento de projetos e ações relacionadas à conscientização ambiental nestas instituições são capazes de mudar a realidade da percepção ambiental dos atores sociais inseridos neste contexto, além de contribuir para o desenvolvimento sustentável global.

A Educação Ambiental enquanto aprendizagem está intimamente ligada aos conhecimentos e instruções transmitidos aos indivíduos no âmbito social, familiar e escolar, de modo que podem influenciar positivamente nas mudanças de hábitos diários. Assim, projetos de Educação Ambiental reiteram sua importância ao passo em que alcançam o objetivo primordial de contribuir para um desenvolvimento mais próximo dos padrões de sustentabilidade.

A aplicação de projetos de Educação Ambiental tem se mostrado uma alternativa válida, pois traz como principais resultados positivos, a contribuição no processo de ensino-aprendizagem dos participantes, participação social nas questões ambientais e a sensibilização sobre os problemas ambientais (OLIVEIRA; OLIVEIRA, 2012; SOUZA et al., 2013; RANCURA et al., 2016;).

No âmbito escolar, acredita-se que a maneira como os atores sociais percebem os diferentes aspectos ambientais é capaz de indicar os pontos a serem trabalhados nas práticas de Educação Ambiental nas escolas e, principalmente a viabilidade para aplicar projetos destinados à conscientização ambiental. 
Desse modo, esta pesquisa objetivou analisar a viabilidade para se realizar projetos de Educação Ambiental em escolas de um bairro do município de João Pessoa-PB, por meio de aplicação de questionários com os principais grupos de participantes: estudantes, docentes e gestores.

\section{Materiais e métodos}

A presente pesquisa caracteriza-se pelo seu cunho exploratório com abordagens quantitativas e qualitativas. Trata-se de um estudo de caso tendo como principal ferramenta de coleta de dados o questionário ${ }^{6}$, possibilitando analisar as respostas dos atores institucionais de escolas públicas e privadas.

Visto a grande quantidade de estudantes, foi realizada uma amostragem tendo como base o cálculo para amostragem aleatória simples sobre variáveis categóricas com erro amostral de $2 \%$ e nível de confiança de $95 \%$. Segundo Santos (2016), para saber de quanto seria este valor, utiliza-se a seguinte fórmula:

$$
n=\frac{N \cdot Z^{2} \cdot P \cdot(1-P)}{Z^{2} \cdot P \cdot(1-P)=e^{2} \cdot(N-1)}
$$

Onde:

$\mathrm{n}$ - amostra calculada

$\mathrm{N}$ - população

Z - variável normal padronizada associada ao nível de confiança

$\mathrm{p}$ - verdadeira probabilidade do evento

e - erro amostral.

Para a amostragem de docentes, foram participantes os professores presentes nas salas de aula no momento da aplicação dos questionários com os estudantes, totalizando-se 23 professores, sendo 13 das escolas públicas e 10 das particulares.

A amostra de gestores participantes da pesquisa foi composta pelos diretores das instituições de ensino de acordo com o acesso a eles, ou seja, os diretores que estavam presentes nas escolas, durante a aplicação dos questionários com os demais participantes.

\section{Área de estudo}

João Pessoa, uma cidade brasileira de médio porte, segundo o IBGE (2010), localiza-se no extremo oriental do estado da Paraíba e ocupa uma área de $210,45 \mathrm{Km}^{2}$. Localiza-se entre as latitudes $7^{\circ} 15^{\prime} 0^{\prime \prime S}$ e $7^{\circ} 3^{\prime} 0^{\prime \prime S}$ e longitudes $34^{\circ} 52^{\prime} \mathrm{W}$ e $34^{\circ} 48^{\prime} 0^{\prime \prime} \mathrm{W}$ (Figura 1).

${ }^{6}$ Avaliado e aprovado pelo Comitê de Ética em Pesquisa (parecer consubstancial: 191.260). 

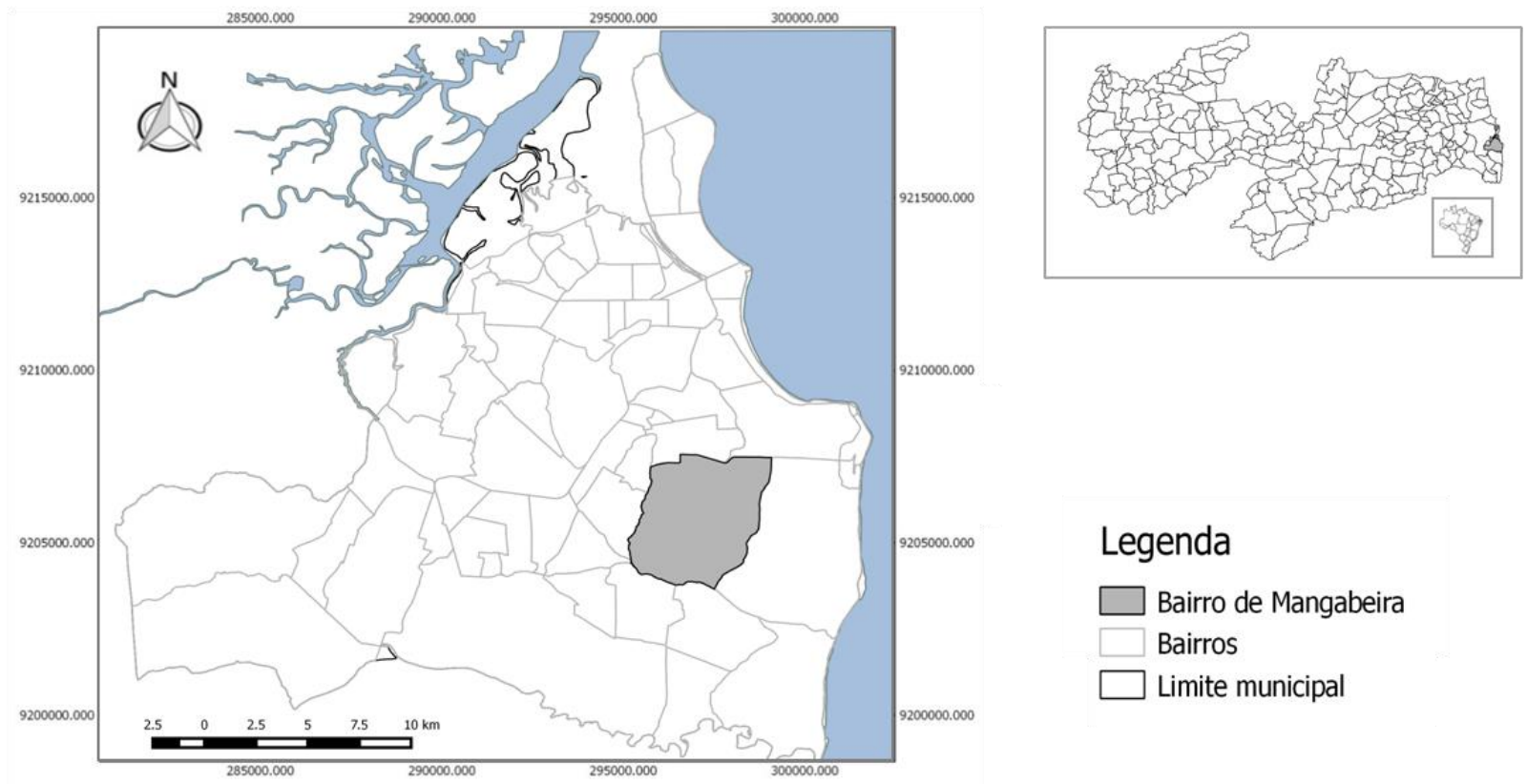

Figura 1: Localização do município de João Pessoa- PB.

Fonte: Elaboração própria (2018).

A cidade atualmente abriga 723.515 habitantes (IBGE, 2010) e junto com o seu crescimento e desenvolvimento urbano, tem apresentado diversos problemas de ordem ambiental, devido, em parte, ao fato de as pessoas não serem sensibilizadas a cuidar do seu meio ambiente.

\section{Resultados e discussões}

No decorrer do desenvolvimento da pesquisa, a aplicação de questionários aos atores sociais foi realizada de acordo com os horários convenientes, de modo a não interferir no curso das aulas e no trabalho dos gestores. A aplicação dos questionários

Abordando os problemas ambientais, inicialmente foi perguntado aos estudantes quem seria (seriam) os responsáveis pela solução destes. Assim, aferiu-se que mais de $75 \%$ dos estudantes das escolas públicas e particulares acredita que os problemas ambientais são de responsabilidade de todos os cidadãos, atribuindo a responsabilidade a comunidade, a toda coletividade (Figura 2, próxima página).

Em sua pesquisa com estudantes do ensino médio, Oliveira et al., (2015), também indicou que uma parcela considerável dos mesmos acredita ser da comunidade a responsabilidade para a resolução dos problemas ambientais.

Entre as quatro alternativas, a resposta "Todos os cidadãos" foi a mais marcada, enquanto "as indústrias" foi escolhida por uma parcela menor de entrevistados. Cabe destacar que $100 \%$ dos estudantes que marcaram "outros" especificaram como sendo "de todos" a responsabilidade na resolução dos problemas ambientais. 


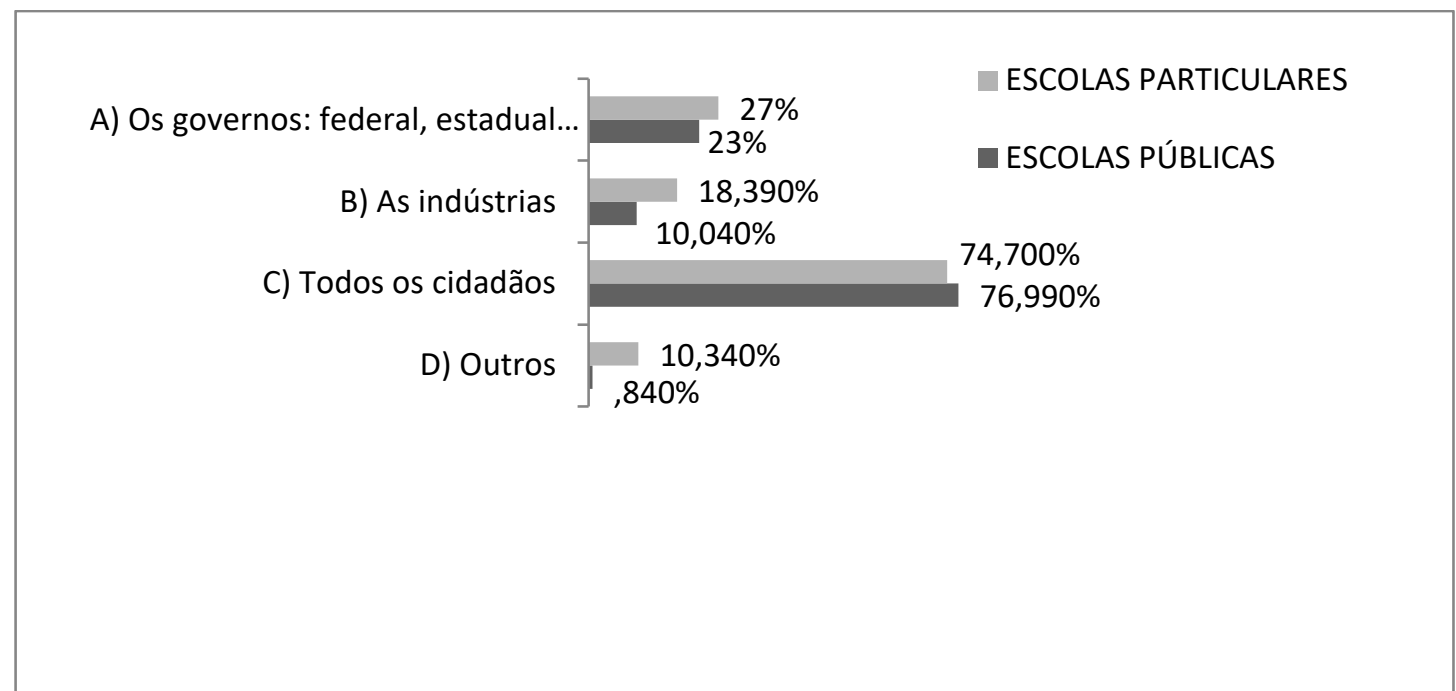

Figura 2: Quem é (são) o(s) responsável (eis) pela solução dos problemas ambientais? Fonte: Dados da pesquisa (2018).

Ao mesmo grupo foi perguntado se os mesmos acham importante que questões ambientais sejam abordadas em sala de aula (Figura 3).

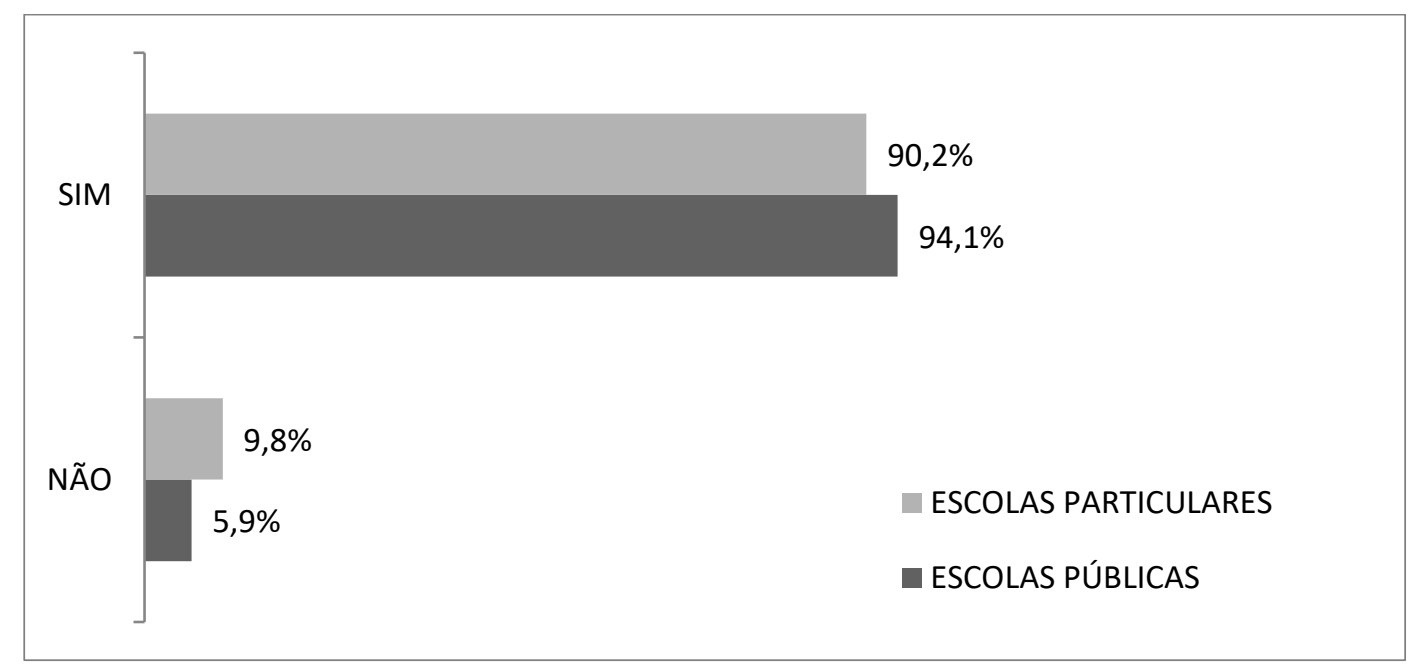

Figura 3: Você acha importante que as questões ambientais sejam abordadas em sala de aula? Fonte: Dados da pesquisa (2018).

Mais de $90 \%$ dos estudantes de ambas as redes de ensino consideram necessário que questões ambientais devem ser abordadas em sala de aula. Este dado é um indicador positivo da importância atribuída pelos alunos nas discussões referentes aos problemas ambientais vivenciados atualmente, o que torna relevante a aplicação de rodas de discussões e debates.

De acordo com Bezerra et al., (2014) a efetivação da Educação Ambiental nas escolas é essencial logo nos primeiros anos de ensino, pois desde a infância os estudantes adquirem um entendimento básico sobre a temática ambiental e, Revbea, São Paulo, V,13, № 1: 272-282, 2018. 
quando mais velhos, suas práticas cotidianas tendem a refletir os seus aprendizados.

Os docentes enquanto monitores e orientadores de projetos de Educação Ambiental são potenciais agentes motivadores dos estudantes por meio de abordagens capazes de apresentar as relações de causa e efeito das ações humanas para com o meio em que vivem, além de mostrar a capacidade do ser humano de transformar a realidade com ações cotidianas.

Por meio da visão de responsabilidade coletiva dos estudantes, os educadores, por exemplo, podem realizar atividades lúdicas que instigam as ações coletivas para contribuir com a recuperação e proteção do meio ambiente na escala local, como na própria escola, bairro ou comunidade.

Nesse sentido, foi indagado aos docentes sobre a responsabilidade pela solução dos problemas enfrentados no meio ambiente (Figura 4).

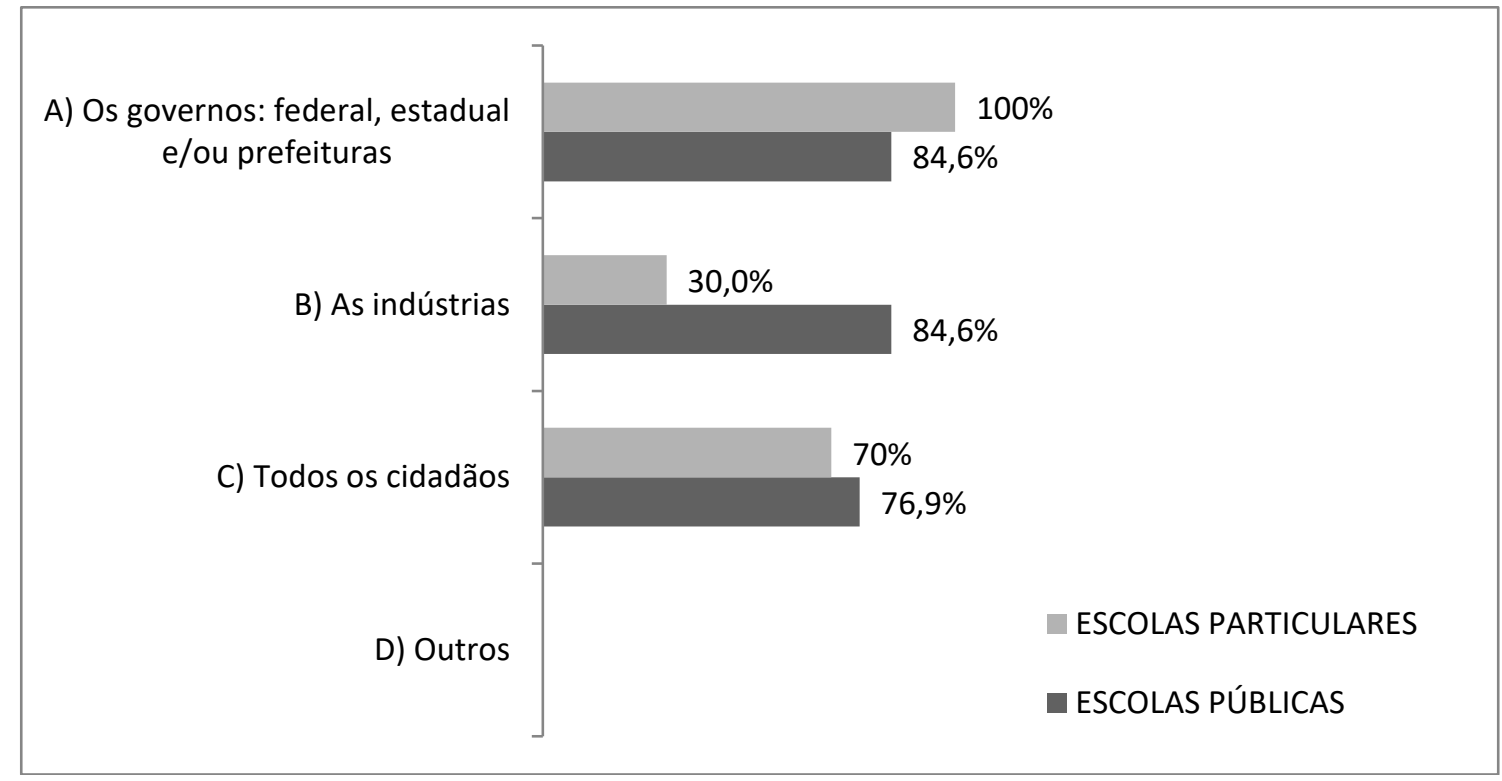

Figura 4: Quem é (são) o(s) responsável (eis) pela solução dos problemas ambientais?

Fonte: Dados da pesquisa (2018).

Os docentes deram respostas múltiplas, ampliando ainda mais a responsabilidade. Para mais de $80 \%$ deles, esta responsabilidade é dividida também pelos governos, que deve ser expressa pela elaboração de leis e normas ambientais, bem como a sua fiscalização. Isto mostra a maturidade uma visão mais ampla, que permeia os deveres da coletividade e questões governamentais que podem ampliar as discussões e reflexões dos estudantes participantes. Uma diferença maior pôde ser vista na alternativa b, onde $50 \%$ de professores das escolas públicas incluíram as indústrias como co-responsáveis.

A Educação Ambiental pode ser considerada como um processo permanente e constante, no qual os indivíduos tornam-se conscientes e sensibilizados acerca do meio ambiente e adquirem conhecimentos, habilidades, 
experiências, valores e a determinação que os tornam capazes de agir, individual ou coletivamente, na busca de soluções para os problemas ambientais (RIGONAT, 2002).

Aos professores, que nas práticas docentes relacionam-se de maneira direta com os estudantes, indagou-se o que vem a ser a Educação Ambiental (Figura 5). Para esta indagação as respostas foram subjetivas e divididas em diferentes categorias.

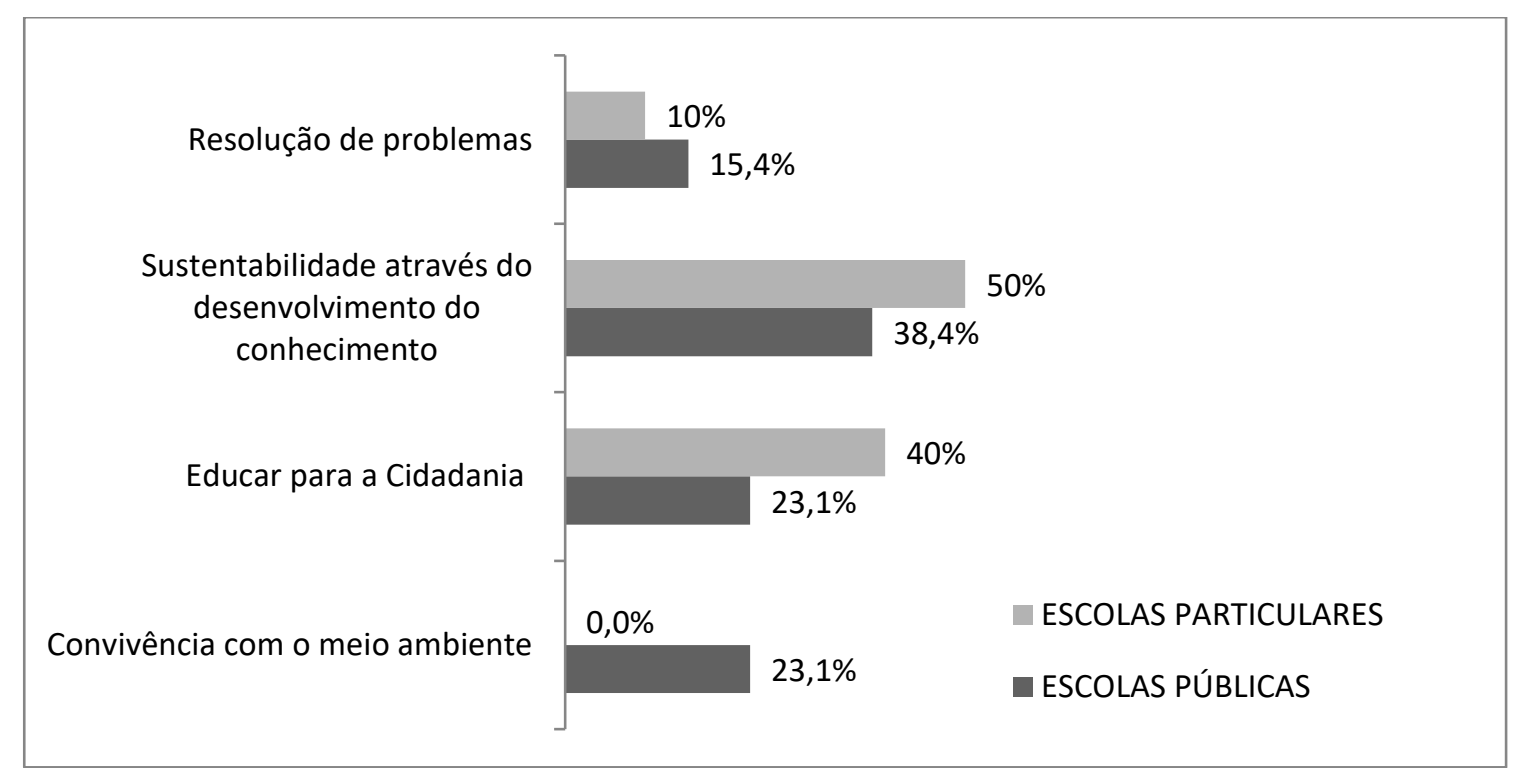

Figura 5: Para você, o que é Educação Ambiental? Fonte: Dados da Pesquisa (2018).

As respostas foram categorizadas em: resolução de problemas, sustentabilidade através do desenvolvimento do conhecimento, educar para a cidadania e convivência com o meio ambiente.

Nota-se que tanto nas públicas como nas privadas, a maioria dos professores tem o foco dos processos de Educação Ambiental voltado para o desenvolvimento do conhecimento como pré-requisito para o alcance da sustentabilidade ( $50 \%$ e $38,4 \%$ respectivamente).

Acredita-se que a forma que o educador percebe a importância da Educação Ambiental tende a influenciar em como se caracterizará a sua abordagem e como serão transmitidas as ferramentas para transformação do meio ambiente. Esta informação é importante para elaboração de treinamentos pedagógicos, tornando-os mais eficazes e efetivos.

O grau de importância que os educadores atribuem à Educação Ambiental pode indicar inclusive a motivação que os mesmos têm de realizar ações de conscientização ambiental por meio de métodos pedagógicos diversos. Desse modo, em outro questionamento, foi possível que eles atribuíssem em uma escala de 0 a 4, a importância da presença da Educação Ambiental, conforme ilustra a Figura 6. 


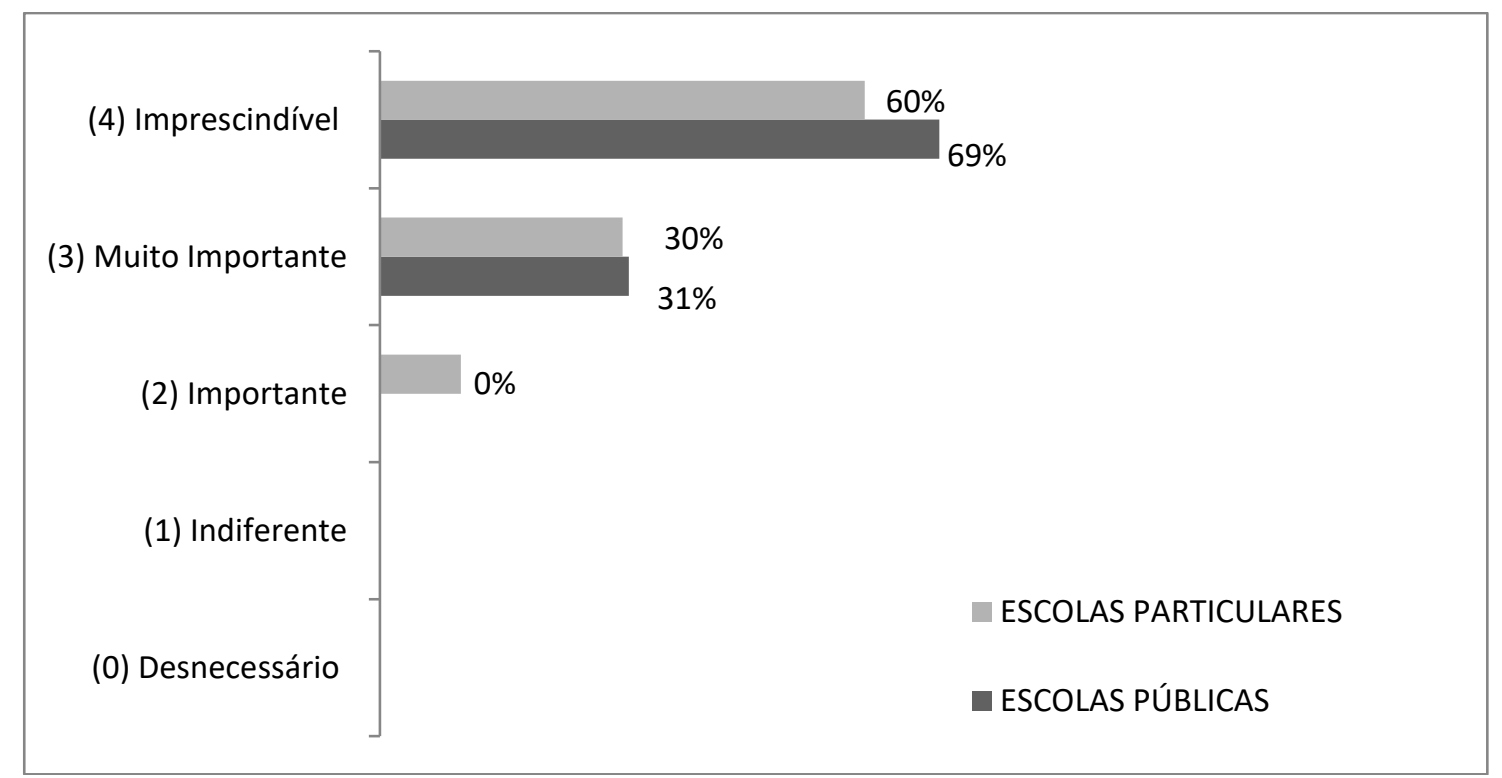

Figura 6: Em uma escala de 0 a 4, qual o grau de importância que você considera a presença da Educação Ambiental no ensino fundamental?

Fonte: Dados da Pesquisa (2018).

A maioria dos educadores de ambas as redes de ensino considerou imprescindível a presença da Educação Ambiental no contexto escolar, enquanto que cerca da metade afirmou considerar a mesma muito importante. Estes dados revelam que os professores reconhecem a necessidade de uma conscientização e sensibilização ambiental por meio da educação.

Aos gestores das escolas foi perguntado sobre o que eles consideram ser a Educação Ambiental. A resposta para a pergunta foi de caráter subjetivo, possibilitando uma maior diversidade de expressão na sua elaboração. Das 7 respostas obtidas foi possível alocar as percepções dos gestores em 3 diferentes categorias: defesa do meio ambiente, educar para a cidadania, e educação doméstica, cujos percentuais encontram-se na Figura 7.

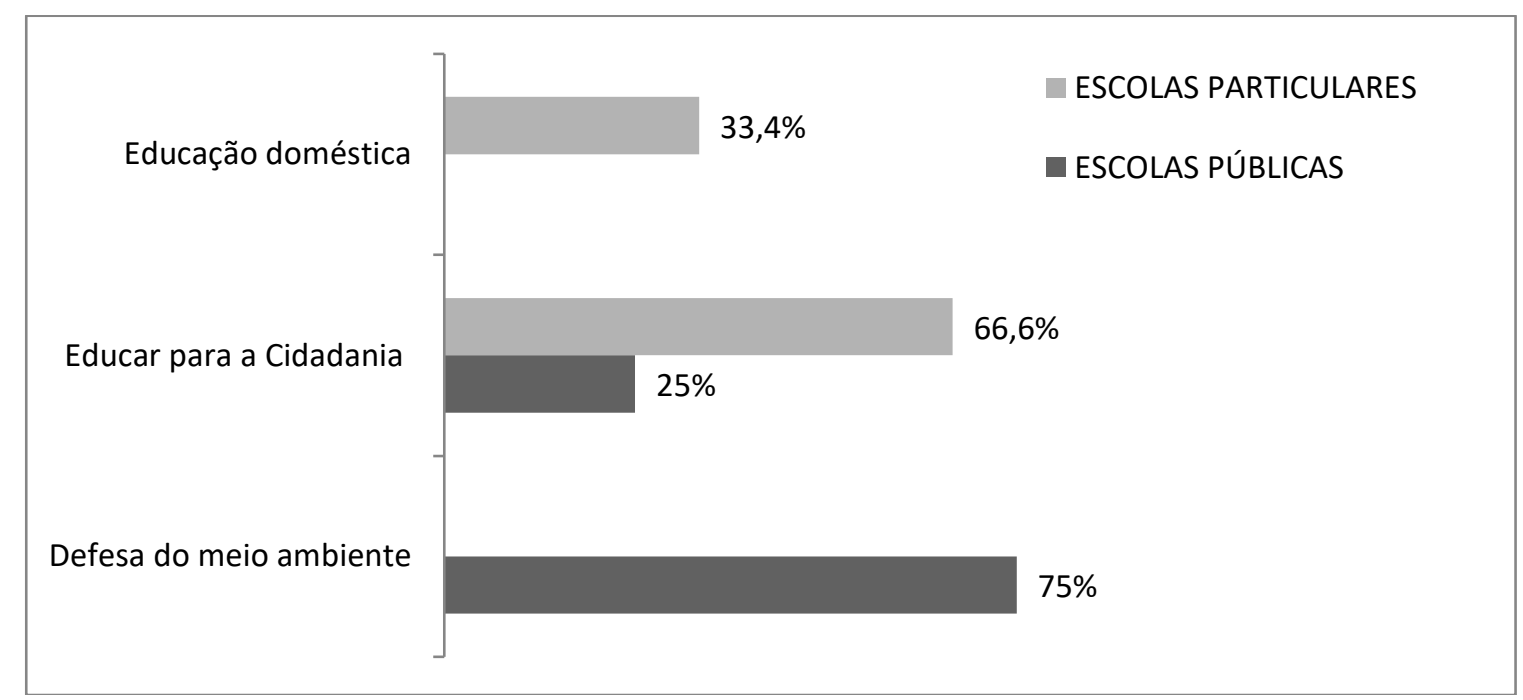

Figura 7: Para você, o que é Educação Ambiental? Fonte: Dados da Pesquisa (2018). 
Os maiores percentuais foram verificados tanto na categoria educar para a cidadania $(66,6 \%)$, como na vertente defesa do meio ambiente $(75 \%)$, sendo a primeira, presente no contexto tanto das escolas públicas como particulares. Isto indica uma convergência de valores no que concerne a relação entre a educação de um modo geral.

Aos gestores também foi solicitado que estabelecessem o grau de importância da Educação Ambiental no ensino fundamental (Figura 8).

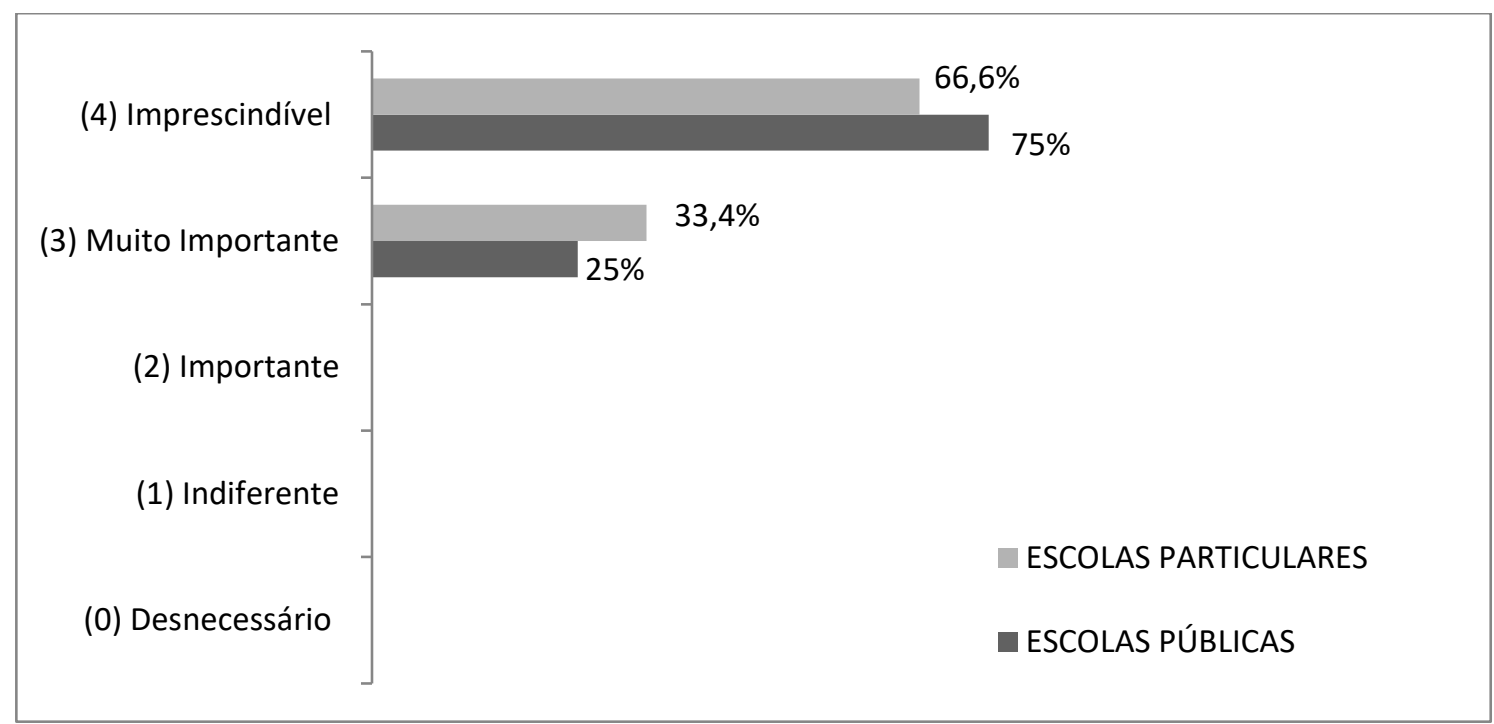

Figura 8: Em uma escala de 0 a 4, qual o grau de importância que você considera a presença da Educação Ambiental no ensino fundamental? Fonte: Dados da Pesquisa (2018).

Os resultados indicaram que a maioria dos gestores julga imprescindível a presença da Educação Ambiental nessa fase da educação formal (66,6\% das privadas e $75 \%$ das escolas públicas), enquanto uma parte menor atribui a ela 0 grau muito importante.

Os resultados do presente estudo, de um modo geral, indicaram haver relevância quantitativas quanto à disposição dos discentes, docentes e gestores nas ações em prol do meio ambiente e a sua capacidade de sentirem-se responsáveis pelas ações que contribuam para resolução dos problemas ambientais.

A maioria dos estudantes também considera importante que haja abordagens sobre as questões ambientais em sala de aula, assim como seus professores. Estes resultados indicam convergências de idéias e valores por parte destes diferentes grupos de atores institucionais, mostrando um potencial positivo nas interações necessárias para realizações de ações de conscientização ambiental no ambiente escolar, importante no processo de busca pela sustentabilidade. 


\section{Conclusões}

Esta pesquisa teve como reflexão primordial o papel sociocultural transformador da Educação Ambiental na realidade atual, que apresenta intensas degradações ambientais decorrentes das ações insustentáveis do ser humano.

Neste contexto, as escolas de ensino fundamental, públicas ou privadas, são essenciais na disseminação de uma consciência ambiental ativa e eficaz, que contribui na motivação e capacitação de atores sociais transformadores da realidade ambiental.

Tendo como base os resultados analisados, foi conclui-se que os estudantes, professores e gestores das instituições de ensino envolvidas na pesquisa, têm consciência da importância da presença da Educação Ambiental no contexto escolar, além de possuírem interesse nas questões relacionadas a problemáticas ambientais.

As escolas envolvidas nesta pesquisa apresentam potencial para efetivação de atividades de Educação Ambiental. No entanto, recomenda-se uma investigação profunda dos fatores que interferem ou podem interferir na aplicação de políticas ambientais no meio escolar.

Ainda foi possível constatar que a aplicação de questionários pode ser uma ferramenta eficiente para um diagnóstico prévio da viabilidade para se implantar projetos de Educação Ambiental em escolas públicas e privadas. Cabe destacar a relevância de se aplicar questionários de avaliação após diferentes etapas de aplicação dos referidos projetos, no sentido de se analisar questões a serem melhoradas e avaliar a importância dos projetos.

Os dados aqui representados poderão servir de subsídio às instituições de ensino públicas e privadas para que estas possam obter uma prévia das percepções ambientais e diagnósticos da motivação no que se refere ao grupo de gestores, docentes e discentes, possibilitando uma gestão ambiental mais eficaz e efetiva.

\section{Referências}

BEZERRA, Y.B.S.; PEREIRA, F.S. P.; SILVA, A.K. P.; MENDES, D.G.P.S. Análise da percepção ambiental de estudantes do ensino fundamental ii em uma escola do município de Serra Talhada (PE). Revista Brasileira de Educação Ambiental, São Paulo, v. 9, n. 2, p.472-488. 2014.

IBGE - Instituto Brasileiro de Geografia e Estatística. Cidades. 2010. Disponível em: <http://cidades.ibge.gov.br/painel/painel.php?codmun=250750> Acesso em: 25 de fevereiro de 2016.

LEFF, E. Complexidade, Interdisciplinaridade e Saber Ambiental. In: PHILIPPI JR., A. et al. Interdisciplinaridade em Ciências Ambientais. São Paulo: Signus, Editora, 2000. 
MARTINS, M.F.; CÂNDIDO, G.A. Índice de Desenvolvimento Sustentável para Municípios (IDSM): metodologia para análise e cálculo do IDSM e classificação dos níveis de sustentabilidade - uma aplicação no Estado da Paraíba. João Pessoa: Sebrae, 2008.

OLIVEIRA, M.E.; OLIVEIRA, A.M.; Educação Ambiental e construção de valores: as práticas pedagógicas aplicadas na Fundação Bradesco - Unidade Ceilândia/DF. Brasileira de Educação Ambiental, Rio Grande, p. 68-79. 2012. RANCURA, K.G.O.; ROCHA, L.O.; TORICELLI, B.; MARTINS, C.; ARAÚJOBISSA, C.H.; Contribuições do projeto de Educação Ambiental "clube tetéia" da fundação parque zoológico de São Paulo para o envelhecimento ativo e a inclusão social de idosos. Revista Brasileira de Educação Ambiental, São Paulo, V. 11, No 4: 269-288, 2016.

SANTOS, G.E.O. Cálculo amostral: calculadora on-line. Disponível em: $<$ http://www.calculoamostral.vai.la $>$. Acesso em: 24 de fevereiro de 2016.

SOUZA, G.S.; MACHADO, P.B.; REIS, V.R.; SANTOS, A.S.; DIAS, V.B. Educação Ambiental como ferramenta para o manejo de resíduos sólidos no cotidiano escolar. Revista Brasileira de Educação Ambiental, Rio Grande, V. 8, No 2:118-130, 2013. 